\title{
Kinetika Ekstraksi Minyak Atsiri Lada Hitam (Piper nigrum) Secara Hidrodistilasi
}

\author{
Kinetics of Black Pepper (Piper nigrum) Essential Oil Extraction by Hydrodistilation
}

\author{
Shintawati $^{\left.1 a^{*}\right)}$, Analianasari ${ }^{1 b)}$, Zukryandry $^{1 c)}$ \\ 1a)Politeknik Negeri Lampung, Teknologi Rekayasa Kimia Industri, Indonesia \\ 1b)Politeknik Negeri Lampung, Pengembangan Produk Agroindustri, Indonesia \\ ${ }^{1 c)}$ Politeknik Negeri Lampung, Teknologi Pangan, Indonesia . \\ *email: shintawati@polinela.ac.id
}

Received: 01/09/20; Revised: 24/10/20; Accepted: 08/11/20

\begin{abstract}
Abstrak
Lada hitam dikenal dengan nama King of Spices yang merupakan salah satu komoditi unggulan ekspor asal Provinsi Lampung. Lada hitam memiliki aroma dan rasa pedas yang khas. Kontribusi aroma berasal dari senyawa volatile yang terkandung pada minyak atsiri dalam lada hitam. Minyak atsiri lada diperoleh dari ekstraksi pelarut, hidrodistilasi, distilasi uap, distilasi fluida super kritik dan hidrodistilasi menggunakan microwave. Nilai konsentrasi minyak atsiri selama ekstraksi serta laju ekstraksi dapat diprediksi dari model kinetika. Tujuan penelitian ini adalah mempelajari ekstraksi minyak atsiri lada hitam dan mengetahui model kinetika ekstraksi minyak atsiri lada hitam secara hidrodistilasi. Hidrodistilasi dilaksanakan selama 5 jam dengan pengambilan data setiap 15 menit. Hasil penelitian memperlihatkan kinetika ekstraksi lada hitam mengikuti model kinetika ekstraksi orde dua. Nilai parameter kinetika orde dua dari ekstraksi minyak atsiri lada hitam yaitu kapasitas ekstraksi minyak atsiri lada,Cs, laju awal ekstraksi, h, dan konstanta laju ekstraksi, $\mathrm{k}$ masing-masing adalah 4,9 $\mathrm{gL}^{-1}, 0,206 \mathrm{~g} \mathrm{~L}^{-1}$ menit ${ }^{-1}$ dan $0,0086 \mathrm{~g}^{-1} \mathrm{~L}$ menit $^{-1}$ dan nilai determinasi sebesar $99,97 \%$. Hasil eksperimen didapat perolehan ekstraksi sebesar 5,14\%.
\end{abstract}

Kata kunci: ekstraksi; hidrodistilasi; kinetika; lada hitam; orde dua

\begin{abstract}
Black pepper known as the King of Spices is one of the leading export commodities from Lampung Province. Black pepper has a distinctive spicy aroma and taste. The aroma contribution comes from the volatile compounds contained in the essential oil of black pepper. Black pepper essential oil is obtained from solvent extraction, hydrodistillation, steam distillation, super critical fluid distillation and hydrodistillation using a microwave. The value of essential oil concentration during extraction and the extraction rate can be predicted from the kinetics model. The purpose of this research was to study the extraction of black pepper essential oil and to know the kinetics model of black pepper essential oil extraction by hydro distillation. Hydro distillation was carried out for 5 hours with data collection every 15 minutes. The results showed that the black pepper extraction kinetics followed the second order kinetics model. The second order kinetics parameter values of black pepper essential oil extraction were the extraction capacity of pepper essential oil, Cs, initial extraction rate, $h$, and extraction rate constant, $k$ respectively. $4.9 \mathrm{~g} \mathrm{~L}^{-1}, 0.206 \mathrm{~g} \mathrm{~L}^{-1}$ minute $e^{-1}$ and $0.0086 \mathrm{~g}^{-1} \mathrm{~L}_{\text {minute }}{ }^{-1}$ and a determination value of $99.97 \%$. The experimental yield extraction is $5.14 \%$.
\end{abstract}

Keywords: black pepper; extraction; hydrodistillation; kinetic; second order 


\section{PENDAHULUAN}

Lada hitam merupakan buah dari tanaman Piper nigrum yang telah dikeringkan yang memiliki rasa dan aroma yang khas. Lada hitam digunakan sebagai bahan pangan rempah, dan mengandung bioaktif yang memiliki manfaat bagi kesehatan antara lain meningkatkan kemampuan cerna terhadap makanan, untuk pengobatan batuk, memperbaiki permasalahan pernafasan, masalah otot jantung, diabetes, anemia serta berpotensi sebagai sediaan obat herbal analgesik, antiinflamasi, antipiretik (Mohammed, 2016).

Minyak atsiri merupakan minyak yang mudah menguap pada tanaman, dan memiliki bau yang khas (Maharaj \& McGaw, 2020) dan dapat dikatakan sebagai "flavor fingerprint" pada rempahrempah (Ruth $d k k$., 2019). Minyak atsiri lada merupakan campuran senyawasenyawa mudah menguap yang diperoleh dari distilasi biji lada kering. Minyak atsiri lada hitam mampu meringankan infeksi pernafasan (Kumoro $d k k$., 2010), meredakan ketegangan otot (Tran $d k k$, 2019) dan memiliki aktifitas antibakteri serta antijamur (Martinelli $d k k$., 2017).

Metode ekstraksi minyak atsiri dari tanaman telah banyak dikembangkan antara lain hidrodistilasi, distilasi uap, microwave hidrodistilasi dan ekstraksi supercritical carbon dioxide (Kumoro dkk., 2010; Maharaj \& McGaw, 2020). Distilasi merupakan proses pemisahan komponen dalam hal ini minyak atsiri dari campurannya berdasarkan perbedaan titik didih (Nisa \& Aminudin, 2019). Metode hidrodistilasi memiliki keunggulan yaitu proses operasional relatif sederhana, biaya pelarut yang rendah, aman bagi lingkungan dan biaya modal yang rendah (Tran $d k k$., 2019).
Kajian kinetika ekstraksi minyak atsiri dari tanaman telah banyak dilakukan. Maharaj \& McGaw (2020) mengkaji model matematik ekstraksi uap minyak atsiri daun basil, berdasarkan perpindahan difusi dan konveksi simultan ke fasa uap. Andras dkk., (2015) mengemukakan kinetika hidrodistilasi minyak atsiri sejumlah tanaman dinyatakan dengan kinetika orde satu. Model kinetika ekstraksi minyak atsiri sandalwood menggunakan persamaan orde dua juga telah dikembangkan oleh Kusuma \& Mahfud (2015) berdasarkan dua proses simultan yang terjadi selama ekstraksi. Karakter kinetika ekstraksi orde dua dicirikan dengan jumlah minyak atsiri yang meningkat cepat di awal ekstraksi dan menurun secara perlahan hingga berakhirnya proses ekstraksi (Kusuma \& Mahfud, 2015).

Kajian model kinetika ekstraksi minyak atsiri lada hitam menggunakan ekstraksi supercritical fluid telah dilakukan oleh Ferreire dkk., (2002) dengan mengembangkan model Lack Plug Flow dan pendekatan mekanisme adsorbsidesorbsi. Kinetika ekstraksi minyak atsiri penting untuk memahami fenomena, mengoperasikan, mengoptimasi, mengendalikan dan merancang distilasi di industri (Milojević $d k k$., 2013; Cassel $d k k$., 2009). Model kinetika berperan untuk mengkaji proses distilasi ditinjau dari teknologi dan keekonomisan proses.

Berdasarkan hasil kajian peneliti sebelumnya, kinetika ekstraksi minyak atsiri tanaman didekati oleh dua proses simultan yaitu difusi dan konveksi yang terwakili oleh model kinetika ekstraksi orde satu dan orde dua. Penelitian ini bertujuan untuk mengkaji ekstraksi minyak atsiri lada hitam secara hidrodistilasi menggunakan dua model kinetika yaitu 
model kinetika ekstraksi orde satu dan orde dua serta mengetahui nilai parameter kinetika yang berkesesuaian.

\section{METODE PENELITIAN}

Penelitian ini dilaksanakan dalam dua tahap yaitu ekstraksi lada hitam menggunakan metode hidrodistilasi serta penentuan model dan parameter kinetika ekstraksi yang paling sesuai.

\section{Alat dan Bahan}

Bahan yang digunakan aquadest, batu didih, dan lada hitam yang berasal dari petani lada di Desa Tegalminangun Kecamatan Sumberejo Kabupaten Tanggamus Provinsi Lampung.

Alat yang digunakan adalah seperangkat alat distilasi Clavenger, timbangan analitis, dan ayakan 40 mesh.

\section{Penyiapan Bahan}

Penyeragaman kadar air biji lada hitam dilakukan dengan menjemur biji lada hitam dibawah sinar matahari selama 2 hari hingga kadar air mencapai 12\%, kemudian lada digiling dan di ayak menggunakan ayakan 40 mesh.

\section{Hidrodistilasi Lada Hitam}

Sebanyak 35 gram lada hitam bubuk ditempatkan dalam labu didih $1 \mathrm{~L}$ dan diberi aquadest sebanyak $350 \mathrm{~mL}$. Distilasi dilaksanakan pada $100^{\circ} \mathrm{C}$ selama 5 jam dengan pengamatan jumlah volume minyak atsiri yang terbentuk setiap 15 menit. Perolehan minyak atsiri dihitung menggunakan persamaan (1) (Kusuma \& Mahfud, 2015).

$$
y=\frac{v}{\mathrm{w}} x 100 \% \text {. }
$$

$\mathrm{y}$ adalah rendemen minyak atsiri lada hitam (\%), v adalah berat minyak atsiri lada hitam yang terekstrak (g) dan w adalah berat lada hitam bubuk (g).

\section{Model dan Parameter Kinetika Ekstraksi Minyak Atsiri Lada Hitam}

Model kinetika ekstraksi dapat dinyatakan sebagai berikut :

\section{Model Kinetika Orde Satu}

Kinetika ekstraksi orde satu bermakna perubahan konsentrasi minyak atsiri setiap saat merupakan fungsi dari selisih antara konsentrasi minyak atsiri dalam keadaan jenuh (Cs) dengan konsentrasi minyak atsiri lada $(\mathrm{Ct})$ saat $\mathrm{t}$ (menit) yang dinyatakan pada persamaan (2) (Kusuma dkk., 2017; Alara \& Abdurahman, 2019).

$\frac{d C t}{d t}=k_{1}(C s-C t)$

dengan $\mathrm{k}_{1}$ adalah konstanta laju ekstraksi minyak atsiri lada hitam orde satu $\left(\mathrm{min}^{-1}\right)$, Cs adalah konsentrasi minyak atsiri lada pada keadaan jenuh yang merupakan kapasitas ekstraksi minyak lada (g $\mathrm{L}^{-1}$ ) dan $\mathrm{Ct}$ adalah konsentrasi minyak atsiri lada ( $\mathrm{g}$ $\mathrm{L}^{-1}$ ) saat $\mathrm{t}$ (menit).

Nilai konstanta laju dan kapasitas ekstraksi minyak atsiri orde satu diperoleh dengan mengintegrasikan persamaan (2) dengan kondisi kondisi batas $\mathrm{Ct}=0$ saat $\mathrm{t}$ $=0$ dan $\mathrm{Ct}=\mathrm{Ct}$ saat $\mathrm{t}=\mathrm{t}$, sehingga diperoleh persamaan (3) berikut:

$\ln \frac{C s}{C s-C t}=k_{1} t$

Menurut Kusuma dkk. (2017), persamaan (3) dapat dinyatakan menjadi persamaan (4). Nilai konstanta laju ekstraksi dan kapasitas ekstraksi orde satu yaitu k1 dan Cs diperoleh dari persamaan regresi linier antara data $\log (\mathrm{Cs}-\mathrm{Ct})$ terhadap t. 


$$
\log (C s-C t)=\log C s-\frac{k_{1}}{2,303} t
$$

\section{Model Kinetika Orde Dua}

Mekanisme kinetika ekstraksi orde dua melibatkan dua proses simultan (Kusuma \& Mahfud, 2015), diawali dengan peningkatan jumlah minyak atsiri yang terekstraksi dengan cepat dan diikuti dengan penurunan laju pembentukan minyak atsiri hingga tercapai keadaan kesetimbangan dimana tidak ada lagi penambahan volume minyak atsiri. Laju ekstraksi minyak atsiri lada hitam yang dinyatakan dengan kinetika orde dua dapat dilihat pada persamaan (5).

$$
\frac{d C t}{d t}=k_{2}(C s-C t)^{2}
$$

dengan $\mathrm{k}_{2}$ adalah konstanta laju ekstraksi minyak atsiri lada hitam orde dua $\left(\mathrm{g}^{-1} \mathrm{~L}\right.$ menit $\left.{ }^{-1}\right)$.

Persamaan (5) diintegrasikan dengan kondisi batas $\mathrm{Ct}=0$ saat $\mathrm{t}=0$ dan $\mathrm{Ct}=\mathrm{Ct}$ saat $\mathrm{t}=\mathrm{t}$ sehingga didapat persamaan (6).

$$
\frac{t}{C t}=\frac{1}{k_{2} C s^{2}}+\frac{t}{C s}
$$

Laju awal ekstraksi dapat dinyatakan dengan h, yaitu $\mathrm{k}_{2} \mathrm{Cs}^{2}$ dimana $\mathrm{Cs}$ merupakan kapasitas ekstraksi minyak atsiri (g L $\left.{ }^{-1}\right)$ (Kusuma $d k k$., 2017). Nilai $h, k_{2}$ dan $C$ s diperoleh dari nilai slope dan intercept garis regresi linier antara data t terhadap $\mathrm{t} / \mathrm{Ct}$.

Kesesuaian model kinetika untuk ekstraksi minyak atsiri lada dievaluasi dari nilai koefisien korelasi, $R$-square dan nilai error yang diwakili oleh nilai MAPE (Mean Absolute Persentage Error), MPE (Mean Persentage Error), MAE (Mean Absolute Error), RMSE (Root Mean Square Error), dan MSE (Mean Square Error) dari masing-masing model kinetika (Alara \& Abdurahman, 2019; Izadifar \& Abdolahi, 2006).

\section{HASIL DAN PEMBAHASAN}

Berdasarkan hasil penelitian, konsentrasi minyak atsiri lada meningkat secara cepat diawal proses ekstraksi hingga menit ke-50, dan melambat setelah menit ke-50. Konsentrasi minyak atsiri lada mencapai nilai maksimum pada menit ke 240 seperti terlihat pada Gambar 1, hal ini menandakan minyak atsiri mencapai keadaan jenuh (Milojević $d k k$., 2013).

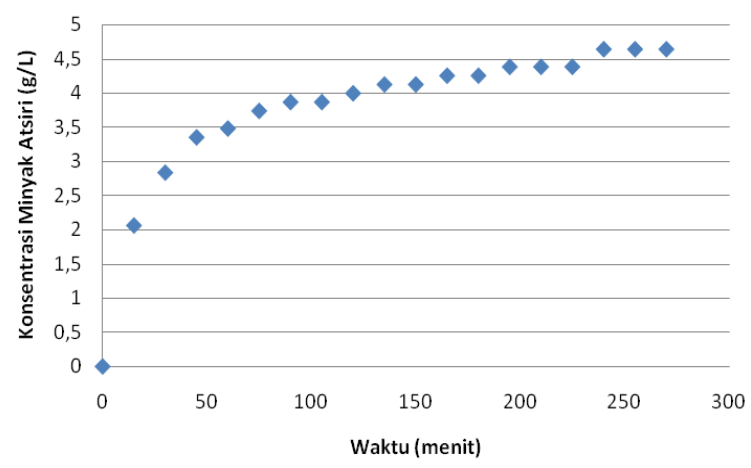

Gambar 1. Konsentrasi Minyak Atsiri Lada Hitam (g/L)

Rendemen diakhir ekstraksi minyak atsiri lada hitam adalah 5,14\%. Nilai rendemen minyak atsiri lada hitam tersebut lebih tinggi dari rendemen minyak lada asal Sajingan Kalimantan Barat, Marroco dan Vietnam masing-masing yaitu 1,27\% (Anggraini $d k k ., 2018$ ), 1,45\% (Rmili $d k k$., 2014) dan 2,45\% (Tran $d k k ., 2019$ ). Nilai rendemen minyak atsiri dipengaruhi spesies tanaman, lokasi tanam, umur panen dan metode distilasi (Rmili dkk., 2014; Filly $d k k ., 2014)$.

Peningkatan temperatur diawal ekstraksi mengakibatkan peningkatan tekanan yang terdapat di dalam bagian tanaman yang mengandung minyak atsiri dan pada tekanan tertentu mengakibatkan pecahnya dinding sel yang diikuti dengan pelepasan minyak atsiri (Maharaj \& McGaw, 2020). Hal tersebut mengakibatkan laju ekstraksi minyak atsiri 
meningkat tajam diawal proses, kemudian diikuti dengan difusi minyak atsiri yang terdapat di bagian dalam bahan baku ke permukaan yang dicirikan dengan melambatnya laju ekstraksi. Fenomena laju ekstraksi yang tinggi diawal proses dan diikuti difusi minyak atsiri dari bagian dalam ke permukaan padatan menjadi ciri khas dari ekstraksi minyak atsiri yang berasal dari tanaman (Milojević dkk., 2013). Asumsi model kinetika yang diusulkan adalah penggabungan kedua fenomena diatas. Sehingga laju ekstraksi dapat didekati dengan beberapa persamaan kinetika yaitu orde satu dan orde dua.

\section{Kinetika Ekstraksi Orde Satu}

Hasil plot $\log (\mathrm{Cs}-\mathrm{Ct})$ terhadap $\mathrm{t}$ sebagaimana Gambar 2 dan dengan menggunakan persamaan (4), diperoleh nilai intercept yang menyatakan besarnya nilai $\log \mathrm{Cs}$, dimana Cs merupakan kapasitas ekstraksi. Nilai konstanta laju ekstraksi peroleh dari nilai kemiringan grafik pada Gambar 2 dikalikan dengan 2,303 (persamaan 4), sehingga diperoleh nilai laju ekstraksi dan kapasitas ekstraksi orde satu masing-masing sebesar 0,0115 (g.L $\mathrm{L}^{-1}$ menit ${ }^{-1}$ ) dan 2,685 (g.L $\mathrm{L}^{-1}$ ) dengan nilai $R$-square 0,9444 .

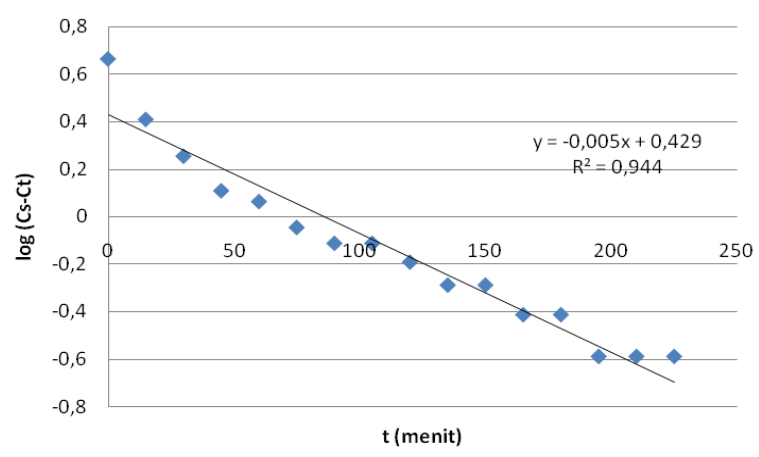

Gambar 2. Kurva Model Kinetika Ekstraksi Minyak Atsiri Lada Hitam Orde Satu

\section{Kinetika Ekstraksi Orde Dua}

Berdasarkan kurva pada Gambar 3, diperoleh slope sebesar 0,204, dari persamaan (6) didapat kapasitas ekstraksi minyak atsiri lada atau Cs model kinetika orde dua adalah 4,9 $\mathrm{g} \mathrm{L}^{-1}$. Sedangkan laju awal ekstraksi, $\mathrm{h}$, yaitu $\mathrm{k}_{2} \mathrm{Cs}^{2}$ diperoleh dari nilai intercept dan persamaan (6) yaitu $0,206 \mathrm{~g} \mathrm{~L}^{-1} \mathrm{menit}^{-1}$. Nilai konstanta laju ekstraksi orde dua, k2, diperoleh menggunakan persamaan (6) yaitu 0,0086 $\mathrm{g}^{-1} \mathrm{~L}^{-1}$ menit ${ }^{-1}$. Nilai $R$-square dari model ekstraksi orde dua ini adalah 0,997.

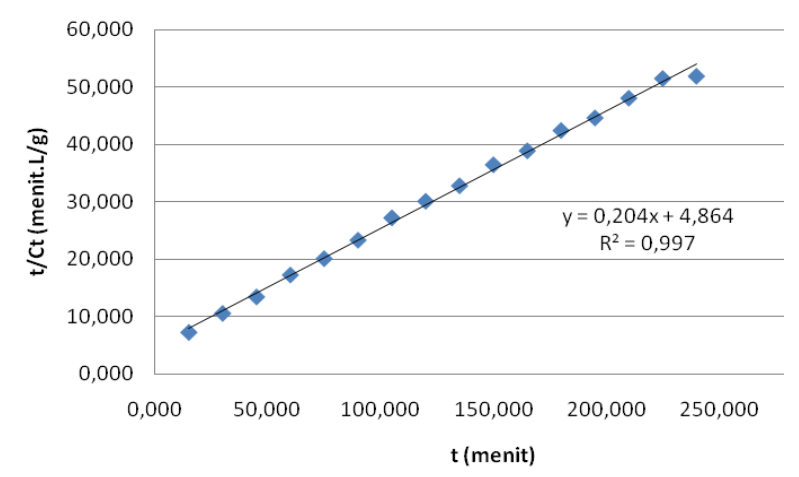

Gambar 3. Kurva Model Kinetika Ekstraksi Minyak Atsiri Lada Hitam Orde Dua

Nilai koefisien determinasi, $\mathrm{R}^{2}$, dari kedua model yang diajukan, nilai $\mathrm{R}^{2}$ model kinetika yang paling mendekati 1 adalah model kinetika orde dua. Hasil perhitungan beberapa fungsi eror terhadap masingmasing model kinetika tertera pada Tabel 1. Model kinetika orde dua memiliki nilai persentase MAPE dan MPE lebih kecil dari model kinetika orde satu, masingmasing sebesar $2,230 \%$ dan $0,271 \%$. Hal tersebut selaras dengan nilai MAE, MSE dan RMSE, sehingga dapat disimpulkan kinetika ekstraksi minyak atsiri lada hitam mengikuti model kinetika ekstraksi orde dua.

Tabel 2 memperlihatkan kinetika ekstraksi minyak atsiri beberapa tanaman 
Kinetika Ekstraksi Minyak Atsiri Lada Hitam (Piper nigrum) Secara Hidrodistilasi

dengan mengikuti model kinetika orde dua

dan konstanta laju ekstraksi, k maupun konsentrasi minyak atsiri keadaan jenuh

(Cs) dipengaruhi oleh spesies tanaman.

Tabel 1. Eror Model Kinetika Ekstraksi Minyak Atsiri Lada Hitam

\begin{tabular}{cccccc}
\hline Model Kinetika & MAE & MSE & RMSE & $\begin{array}{c}\text { MAPE } \\
(\boldsymbol{\%})\end{array}$ & $\begin{array}{c}\text { MPE } \\
(\boldsymbol{\%})\end{array}$ \\
\hline Orde Satu & 0,238 & 0,488 & 0,698 & 45,32 & 14,60 \\
Orde Dua & 0,077 & 0,009 & 0,094 & 2,230 & 0,271 \\
\hline
\end{tabular}

Tabel 2. Kinetika Ekstraksi Minyak Atsiri Berbagai Tanaman

\begin{tabular}{cccccccc}
\hline Tanaman & Metode & Orde & $\begin{array}{c}\mathbf{C s} \\
\left(\mathbf{g L}^{-1}\right)\end{array}$ & $\mathbf{k}$ & $\begin{array}{c}\mathbf{h} \\
\left(\mathbf{g ~ L}^{-1} \mathbf{m i n}^{-\mathbf{1}}\right)\end{array}$ & $\mathbf{R}^{\mathbf{2}}$ & Ref. \\
\hline Sandalwood & $\begin{array}{c}\text { Microwave } \\
\text { Vydrodistilation }\end{array}$ & 2 & 0,6015 & 0,0642 & 0,0232 & 0,9597 & Kusuma \& Mahfud, \\
Lertiver & $\begin{array}{c}\text { Microwave } \\
\text { Lydrodistilation } \\
\text { Hidrodistilasi }\end{array}$ & 2 & 6,2189 & 0,0007 & 0,029 & 0,9427 & Kusuma $d k k ., 2017$ \\
& 2 & 4,9 & 0,0086 & 0,206 & 0,997 & Penelitian ini \\
\hline
\end{tabular}

\section{KESIMPULAN}

Ekstraksi minyak atsiri lada hitam secara hidrodistilasi menghasilkan rendemen eksperimen sebesar $5,14 \%$ dengan kinetika ekstraksi mengikuti model kinetika orde dua. Nilai parameter kinetika ekstraksi minyak atsiri lada hitam yaitu kapasitas ekstraksi minyak atsiri lada,Cs, laju awal ekstraksi, h, dan konstanta laju ekstraksi, k masing-masing adalah $4,9 \mathrm{~g} \mathrm{~L}^{-}$ 1, 0,206 $\mathrm{g} \mathrm{L}^{-1}$ menit $^{-1}$ dan 0,0086 $\mathrm{g}^{-1} \mathrm{~L}^{-}$ ${ }^{1}$ menit $^{-1}$, dengan nilai determinasi sebesar $99,7 \%$. Berdasarkan penelitian ini perlu dikembangkan kajian untuk mendapatkan rendemen minyak atsiri yang optimal melalui penggunaan metode distilasi yang berbeda seperti microwave hydrodistilation.

\section{DAFTAR RUJUKAN}

Alara O. R. \& Abdurahman N. H. (2019). Kinetics Studies On Effects Of Extraction Techniques On Bioactive Compounds From Vernonia cinerea Leaf. J Food Sci Technol., 56, 580588. https://doi.org/10.1007/s13197018-3512-4.
Andras, C.D., Volf, I., Salamon R.,V., Barabas, I., \& Szep, A. (2015). Influence of Extraction Methods On Caraway (carum carvi 1.) Essential Oil Yield And Carvone/Limonene Ratio. Environmental Engineering and Management Journal, 14(2), 341-347.

https://doi.org/10.30638/eemj.2015.0 $\underline{34}$

Anggraini, R., Jayuska, A., \& Alimuddin, A.H. (2018). Isolasi dan Karakterisasi Minyak Atsiri Lada Hitam (Piper nigrum 1.) Asal Sajingan Kalimantan Barat. Jurnal Kimia Khatulistiwa, 7(4), 124-133.

Cassel, E.,Vargas, R.M.F., Martinez, N.,Lorenz, D. \& Dellacassa, E. (2009). Steam Distillation Modeling for Essential Oil Extraction Process. Industrial Crops And Products, 29(1), 171-176. https://doi.org/10.1016/j.indcrop.200 8.04.017.

Filly, A., Fernandez. X., Minuti, M., Chemat, F., Visinoni, F., \& Cravotto, G. (2014). Solvent-free Microwave Extraction Of Essential Oil From Aromatic Herbs : From Laboratory to Pilot And Industrial Scale. Food Chemistry, 1(150), 193-198. 
https://doi.org/10.1016/j.foodchem.2 013.10.139.

Izadifar, M., \& Abdolahi F. (2006). Comparison Between Neural Network and Mathematical Modeling Of Supercritical $\mathrm{CO}_{2}$ Extraction Of Black Pepper Essential Oil. J. of Supercritical Fluids, 38(1), 37-43.

https://doi.org/10.1016/j.supflu.2005. 11.012 .

Kumoro, A. C., Hasan, M. \& Singh, H. (2010). Extraction of Sarawak Black Pepper Essential Oil Using Supercritical Carbon Dioxide. The Arabian Journal for Science and Engineering, 35(2B), 7-16. https://pdfs.semanticscholar.org/d7fd /f7cecf4a3e76

Kusuma, H. S., \& Mahfud, M. (2015). Preliminary Study: Kinetics of Oil Extraction from Sandalwood by Microwave-assisted

Hydrodistillation. ASEAN Journal of Chemical Engineering, 15(2), 62-69. https://doi.org/10.22146/ajche.49687

Kusuma, H.S., Rohadi, T.I., Daniswara, E.F., Altway, A. \& Mahfud. (2017). Preliminary Study: Comparison of Kinetic Models of Oil Extraction from Vetiver (Vetiveria Zizanioides) by Microwave Hydrodistillation. Korean Chem. Eng. Res., 55(4), 574577.

https://doi.org/10.9713/kcer.2017.55. $\underline{4.574}$

Maharaj, S. \& McGaw, D. (2020). Mathematical Model for the Removal of Essential Oil Constituents during Steam Distillation Extraction. Processes, 8(400), 2-13. https://doi.org/10.3390/pr8040400.

Martinelli, L., Rosa, J.M., Ferreira C.,S.,B., Nascimento G.,M.,L., Freitas, M.S., Pizato, L.C., Santos W.,O., Pires, R.F., Okura, M.H., Malpass G.R.P., \& Granato, A.C. (2017). Antimicrobial Activity And Chemical Constituents Of Essential
Oils And Oleoresins Extracted From Eight Pepper Species. Ciência Rural, Santa Maria, 47(05), 1-7. http://dx.doi.org/10.1590/0103$8478 \mathrm{cr} 20160899$.

Milojević, S.Z., Radosavljević D.B., Pavićević V. P., Srđan,P., \& Veljković V., B. (2013). Modeling The Kinetics of Essential Oil Hydrodistillation from Plant Materials. Hemijska Industrija, 67(5), 843-859. https://doi.org/10.2298/HEMIND121 026009M.

Mohammed, G.,J., Omran, A.,M., \& Hussein H.M. (2016). Antibacterial and Phytochemical Analysis of Piper nigrum using Gas Chromatography Mass Spectrum and FourierTransform Infrared Spectroscopy. International. Journal of Pharmacognosy and Phytochemical Research, 8(6), 977-996. http://impactfactor.org/PDF/IJPPR/8/ IJPPR, Vol8,Issue6, Article14.pdf

Nisa N., I., F. \& Aminudin, A. (2019). Pengaruh Waktu Distilasi Etanol-Air Terhadap Konsentrasi Overhead Product dan Bottom Product. Chemical Engineering Research Articles, 2(1), 19-25. http://doi.org/10.25273/cheesa.v2i1.4 $\underline{469}$

Rmili R., Ramdani, M., Ghazi, Z., Saidi, N., \& Mahi, B.,E. (2014). Composition Comparison Of Essential Oils Extracted by Hydrodistillation and MicrowaveAssisted Hydrodistillation from Piper nigrum L. J. Mater. Environ. Sci., 5(5), 1560-1567. https://www.jmaterenvironsci.com/D ocument/vol5/vol5_N5/167-JMES917-2014-Rmili.pdf

Ruth, S.M., Jensen M., Silvis, I.,C.,J., A, Ramos, M.E., Luning, P.A., Elliott, C.,T., \& Alewijen, M. (2019), Cool comparison of black and white pepper grades. Food Science and Technology, 106, 122-127. 
https://doi.org/10.1016/j.lwt.2019.02. 054.

Tran, T.H., Ha L.K., Nguyen D.C., Nhan L.,T.,H., Nguyen D.,H., Nguyen T.,D.,Vo D.,V.,N., Tran , Q.,T. \& Bach L.,G. (2019). The Study on Extraction Process and Analysis of Components in Essential Oils of Black Pepper (Pipernigrum L.) Seeds Harvested in Gia Lai Province,Vietnam. Processes, 7(56), 2-16.

https://doi.org/10.3390/pr7020056 